TAVEIRA, R.Z. et al. Avaliação quantitativa de características produtivas e medidas lineares em rebanho leiteiro da raça Holandesa. PUBVET, Londrina, V. 8, N. 1, Ed. 250, Art. 1654, Janeiro, 2014.

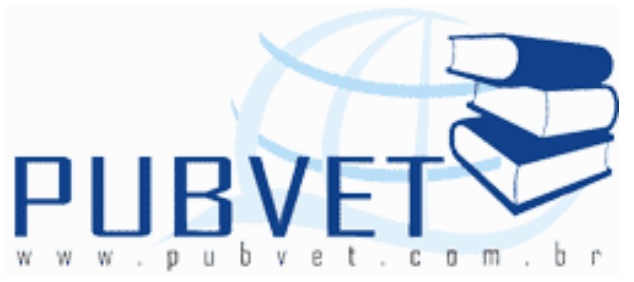

PUBVET, Publicações em Medicina Veterinária e Zootecnia.

\title{
Avaliação quantitativa de características produtivas e medidas lineares em rebanho leiteiro da raça Holandesa
}
Rodrigo Zaiden Taveira ${ }^{1}$, Osvaldo José da Silveira Neto ${ }^{1}$, Thais Nunes Luz ${ }^{2}$, Ana Anária Alvarenga Leite ${ }^{2}$, Bruna Cristhina de Oliveira ${ }^{3}$, Taynara Raimundo Martins $^{3}$

${ }^{1}$ Docente e Pesquisador - curso de Zootecnia - UEG - UnU - São Luís de Montes Belos.

${ }^{2}$ Bolsista PBIC/UEG - acadêmica do curso de Zootecnia - UEG - UnU - São Luís de Montes Belos.

${ }^{3}$ Acadêmica do curso de Zootecnia - UEG - UnU - São Luís de Montes Belos.

\section{Resumo}

A maximização da produção de leite vem por muito tempo sendo foco de seleção nos rebanhos que se destinam a essa função econômica, entretanto, percebe-se o descarte precoce de vacas de média a alta produção em virtude do comprometimento de características funcionais importantes, tais como aprumos e aspectos relacionados ao sistema mamário. As vacas possuidoras de melhores características funcionais podem permanecer por maior tempo no rebanho, desde que sejam boas produtoras de leite, tendo a chance de produzir mais filhas que poderão ser incorporadas ao plantel ou disponibilizadas para a venda, agregando importante receita ao produtor de leite.O estudo foi conduzido num rebanho leiteiro localizado no município de 
TAVEIRA, R.Z. et al. Avaliação quantitativa de características produtivas e medidas lineares em rebanho leiteiro da raça Holandesa. PUBVET, Londrina, V. 8, N. 1, Ed. 250, Art. 1654, Janeiro, 2014.

São Luís e Montes Belos, GO. Foram utilizadas 50 vacas da raça Holandesa, num mesmo estádio de lactação, das quais se avaliou a produção de leite ajustada para 305 dias, além de 07 medidas lineares de tipo. As medidas lineares foram correlacionadas entre si e com a produção de leite, através da correlação de Pearson. Foram avaliados ainda os escores pra ângulo de garupa e curvatura das pernas, numa escala que variava de 01 a 09, além da largura de boca, numa escala de 01 a 05.A produção de leite média até 305 dias encontrada nesse estudo foi de $9.860,65 \mathrm{~kg}$ de leite. O peso corporal médio encontrado foi de $658,70 \mathrm{~kg}$. Pode ser adotada a seleção a favor de menor tamanho corporal das vacas e melhor curvatura de pernas, tendo em vista a melhor relação custo - benefício entre os custos de produção do leite e a produtividade dos animais.A maior correlação encontrada ocorreu entre a produção de leite diária e a largura de úbere posterior, indicando que as vacas possuidoras de maior valor desta medida, tendem a produzir mais leite, podendo, portanto, ser incluída no critério de seleção do rebanho.

Palavras-chave: avaliação visual; produção leiteira.

\title{
Quantitative evaluation of productive traits and linear measures in dairy cattle of Holstein breed
}

\begin{abstract}
The milk production maximization have been being by several years selected in the livestock that do this economical function, however, can be observed that the precocity sell of cows from median to high production, due problems in the important functional traits, as aplomb and aspects relationship to the mammary system. The cows that have the best functional traits can be kept in the livestock by more time, but, they should be good milk producers, having the chance to produce more daughters that can be incorporate into the livestock or sold, aiming important gains to the milk producer. The study was conducted in a dairy livestock located in the São Luís de Montes Belos city, Goiás state. There were evaluated 50 cows of Holstein breed, in the same
\end{abstract}


TAVEIRA, R.Z. et al. Avaliação quantitativa de características produtivas e medidas lineares em rebanho leiteiro da raça Holandesa. PUBVET, Londrina, V. 8, N. 1, Ed. 250, Art. 1654, Janeiro, 2014.

lactation stadium, evaluated the daily milk production, the milk production adjusted by 305 days of each animal and 07 type linear measures. The linear measures were themselves correlated and with the milk production, by the Pearson correlation. It was evaluate the scores for ramp angulation and legs angulation, considering scale from 01 to 09 , and mouth width, considering scale from 01 to 05 . The average milk production until 305 days found in this study was $9,860 \mathrm{~kg}$ of milk. The average body weight was $658.70 \mathrm{~kg}$. Could be observed that $46 \%$ and $36 \%$ of the animal showing the ramp angulation and legs angulation in the 07 score. Can be adopted the selection considering the less corporal size and better legs angulation, aiming the better benefice - cost relationship between milk production costs and animals productive. The highest phenotypic correlation occurred between the daily milk production and the posterior uberous width, showing that the cows with this higher measure, trend to produce more milk, should, therefore, include in the selection criteria of the livestock.

Keywords: dairy production; Holstein cow; visual evaluation.

\section{Introdução}

O potencial de produção leiteiro de uma vaca é muito variado, devido às diversas condições ambientais e sistemas de produção distintos aos que os animais são submetidos.Nesse sentido, as avaliações quantitativas de características produtivas e medidas lineares em rebanhos leiteiros devem ser realizadas, no intuito de identificar os biótipos superiores dentro de cada sistema específico.

A ênfase no processo de seleção de gado leiteiro é dada para características de produção, já que vacas de alta produção geram maior lucro, especialmente se a vaca apresentar alta produção de leite nas primeiras lactações, sendo ainda funcional por longo período dentro do rebanho. Porém, a seleção praticada exclusivamente para produção de leite pode diminuir o mérito de outras características (MISZTAL et al., 1992). 
TAVEIRA, R.Z. et al. Avaliação quantitativa de características produtivas e medidas lineares em rebanho leiteiro da raça Holandesa. PUBVET, Londrina, V. 8, N. 1, Ed. 250, Art. 1654, Janeiro, 2014.

Atualmente sabe-se da necessidade em conhecer as relações existentes entre as características morfométricas e destas com a produção de leite. $\mathrm{O}$ entendimento dessas associações pode facilitar o processo de seleção e promover maiores ganhos genéticos por unidade de tempo, desde que se perceba como a seleção para tipo influencia na produção de leite.

A avaliação das características de lineares identifica aquelas que mais se associam a produtividade dos animais, considerando ainda aspectos relacionados ao maior tempo de permanência dos animais nos rebanhos, como bons aprumos e estrutura corporal adequada.

Características de tipo devem merecer atenção quando o objetivo é maximizar a vida produtiva do animal, evitando descartes precoces por problemas de aprumos e ligamentos, dentre outros (ESTEVES et al., 2004).

Face ao exposto, objetivou-se constatar os valores médios da produção de leite, peso corporal e medidas morfométricas em vacas da raça Holandesa, além de estimar correlações entre a produção de leite diária e a produção de leite ajustada para 305 dias com as medidas lineares, além de constatar os biótipos mais frequentes no rebanho, tendo em vista a angulação de garupa e curvatura das pernas.

\section{Material e Métodos}

O estudo foi conduzido num rebanho leiteiro localizado no município de São Luís e Montes Belos, GO. Foram utilizadas 50 vacas da raça Holandesa, num mesmo estádio de lactação, das quais se aferiu o peso corporal, produção diária de leite e produção de leite ajustada para 305 dias.

Foram mensuradas07 medidas lineares de tipo, sendo: comprimento dos tetos; largura de íleo; largura de ísquio; perímetro torácico; comprimento corporal; altura de garupa e largura de úbere posterior.

O comprimento dos tetos foi medido entre a inserção dos tetos no úbere e a extremidade final dos tetos, utilizando-se fita métrica graduada em $\mathrm{cm} . \mathrm{A}$ largura de íleos elargura de ísquios foi avaliada por meio da distância entre 
TAVEIRA, R.Z. et al. Avaliação quantitativa de características produtivas e medidas lineares em rebanho leiteiro da raça Holandesa. PUBVET, Londrina, V. 8, N. 1, Ed. 250, Art. 1654, Janeiro, 2014.

seus pares, utilizando-se para isso fita métrica graduada em $\mathrm{cm} .0$ perímetro torácico foiobtido utilizando-se fita métrica específica graduada em $\mathrm{cm}$, circundando o animal pela cernelha e cilhadouro. O comprimento corporal foi medido em linha reta entre a articulação escápulo-umeral à tuberosidade coxal do íleo, utilizando-se fita métrica graduada em $\mathrm{cm}$. A altura da garupa foi mensurada com hipômetro, medindo-se a altura do osso sacro até o chão.A largura do úbere posterior foi realizada na região aonde termina o tecido secretor de leite, utilizando-se fita métrica graduada em $\mathrm{cm}$.

Foram avaliadosos escores pra ângulo de garupa e curvatura das pernas, numa escala que variava de 01 a 09 . No caso da primeira característica, as notas mais baixas indicaram garupas mais invertidas, enquanto queas mais altas indicaram garupas mais inclinadas. Tendo em vista a segunda característica, as notas mais baixas associaram-se a pouca curvatura das pernas, enquanto as mais altas recaíram sobre pernas mais curvas. A largura da boca foi avaliada numa escala que variava de 01 a 05 , sendo que as maiores notas indicaram bocas maiores.

As medidas lineares foram correlacionadas entre si e com a produção de leite ajustada para 305 dias por meio da correlação de Pearson.Os coeficientes de correlação de Pearson entre as características consideradas foram calculados utilizando o procedimento CORR, com $1 \%$ de probabilidade.

As médias e os desvios-padrões das características foram calculados pelo programa estatístico SAS (2003) e os coeficientes de variação foram obtidos dividindo-se o desvio-padrão pela média e multiplicando-se por 100.

\section{Resultados e Discussão}

A tabela 1 dada abaixo apresenta as médias, desvios-padrões e coeficientes de variação para o peso corporal, produção de leite diária e produção total de leite em 305 dias. 
TAVEIRA, R.Z. et al. Avaliação quantitativa de características produtivas e medidas lineares em rebanho leiteiro da raça Holandesa. PUBVET, Londrina, V. 8, N. 1, Ed. 250, Art. 1654, Janeiro, 2014.

Tabela 1. Médias, desvios-padrões e coeficientes de variação para o peso corporal, produção de leite diária e produção total de leite ajustada para 305 dias de vacas da raça Holandesa.

\begin{tabular}{ccc}
\hline Caraterística & Média \pm DP & CV (\%) \\
\hline Peso corporal $(\mathrm{Kg})$ & $658,70 \pm 67,20$ & 10,20 \\
Produção de leite diária $(\mathrm{Kg})$ & $32,33 \pm 5,71$ & 17,66 \\
Produção total de leite em 305 dias & $9.860,65 \pm 987,43$ & 10,01 \\
$(\mathrm{Kg})$ & & \\
\hline
\end{tabular}

A produção de leite média ajustada para 305 dias encontrada nesse estudo foi de $9.860,65 \mathrm{~kg}$ de leite, cerca de $2.825,65 \mathrm{~kg}$ e $5.226,65 \mathrm{~kg}$ inferiores aos $7.035 \mathrm{~kg}$ e $4.634 \mathrm{~kg}$ encontrados por Freitas et al. (2000) e Zambianchi et al. (1999), respectivamente, em vacas da raça Holandesa, criadas em sistema de produção semelhante ao desse estudo.

O peso corporal médio das vacas encontrado foi de $658,70 \mathrm{~kg}$, demonstrando que as mesmas encaixam-se num padrão de grande porte, exigindo maior aporte nutricional e exigindo maior atenção nos aspectos reprodutivos do rebanho.

A tabela 2 apresenta as médias, desvios-padrões e coeficientes de variação de caraterísticas lineares de tipo em vacas da raça Holandesa.

O comprimento médio dos tetos das vacas encontrado nesse estudo foi de $5,41 \mathrm{~cm}$, evidenciando que o rebanho encontra-se sob seleção para essa característica.

A largura da boca é uma medida que começa a ganhar importância nos programas de seleção, podendo indicar que maiores valores associam-se a maior capacidade de aporte de alimento, seja por pastejo ou em consumo de concentrado. O resultado encontrado nesse estudo indicou que $46 \%$ das vacas apresentaram escore 3, indicando tamanho de boca de moderado a grande. 
TAVEIRA, R.Z. et al. Avaliação quantitativa de características produtivas e medidas lineares em rebanho leiteiro da raça Holandesa. PUBVET, Londrina, V. 8, N. 1, Ed. 250, Art. 1654, Janeiro, 2014.

A largura entre ísquios e íleos possui contribuição na facilidade de partos das vacas, o que pode ser dificultoso na raça Holandesa. Os valores encontrados nesse estudo foram de 34,66 e 51,92 cm, respectivamente para a primeira e segunda característica, não contribuindo para que haja ocorrência de partos problemáticos.

Tabela 2. Médias, desvios-padrões e coeficientes de variação do comprimento dos tetos, largura de íleo, largura de ísquio, perímetro torácico, comprimento corporal, altura de garupa e largura de úbere posterior em vacas da raça Holandesa.

\begin{tabular}{ccc}
\hline Característica & Média \pm DP & CV (\%) \\
\hline Comprimento dos tetos $(\mathrm{cm})$ & $5,41 \pm 0,82$ & 15,15 \\
Largura de íleo $(\mathrm{cm})$ & $51,92 \pm 5,46$ & 10,51 \\
Largura de ísquio $(\mathrm{cm})$ & $34,66 \pm 3,41$ & 9,83 \\
Perímetro torácico $(\mathrm{cm})$ & $175,23 \pm 20,35$ & 11,61 \\
Comprimento corporal $(\mathrm{cm})$ & $99,20 \pm 11,12$ & 11,20 \\
Altura de garupa $(\mathrm{cm})$ & $131,23 \pm 10,98$ & 8,36 \\
Largura de úbere posterior & $14,10 \pm 2,42$ & 17,16 \\
$(\mathrm{~cm})$ & & \\
\hline
\end{tabular}

A largura média do úbere posterior encontrada nesse estudo foi de 14,10 $\mathrm{cm}$, indicando úberes largos, proporcionando maior armazenamento de leite sem acrescentar profundidade, o que livra as vacas de traumas mecânicos de úberes causados por atrito com sujidades nas pastagens.

A tabela 3 dada abaixo apresenta a classificação de escores para as características de ângulo de garupa e curvatura das pernas em vacas da raça Holandesa. 
TAVEIRA, R.Z. et al. Avaliação quantitativa de características produtivas e medidas lineares em rebanho leiteiro da raça Holandesa. PUBVET, Londrina, V. 8, N. 1, Ed. 250, Art. 1654, Janeiro, 2014.

Tabela 3. Escore (\%) para as características de ângulo de garupa, ângulo de cascos e curvatura das pernas em vacas da raça Holandesa.

\begin{tabular}{cccccc}
\hline & \multicolumn{5}{c}{ Escore (\%) } \\
Característica & 01 & 03 & 05 & 07 & 09 \\
\hline Ângulo de garupa & 2,0 & 2,0 & 36,0 & 46,0 & 14,0 \\
Curvatura das & 18,0 & 14,0 & 24,0 & 36,0 & 8,0 \\
pernas & & & & & \\
\hline
\end{tabular}

Tendo em vista a análise da tabela 3, pode ser constatado que o ângulo de garupa e curvatura de pernas apresentou maiores porcentagens, $46 \%$ e $36 \%$, respectivamente, situadas no escore 07 . No caso da primeira caraterística, observa-se que esse escore indica que $46 \%$ das vacas avaliadas possuíam ângulo de garupa tendendo a inclinada, com o osso ísquio mais baixo que o íleo, ajudando na facilidade de parto. No caso da segunda característica, constata-se que esse escore indica que $36 \%$ das vacas avaliadas apresentavam curvatura de pernas pouco além do desejado, devendo, portanto, ser considerada no programa de seleção da propriedade.

A tabela 4 apresenta as estimativas de correlações simples da produção de leite diária e produção de leite ajustada para 305 dias com características morfométricas em vacas da raça Holandesa.

As correlações simples entre características lineares de tipo e produção de leite variaram de baixas a moderadas, $(-0,06$ a 0,23$)$. As baixas estimativas decorrelações encontradas nesse estudo apresentam-se em concordância com as estimativas observadas por BROTHERSTONE (1994), que também pesquisou essas associações em rebanho da raça Holandesa. 
TAVEIRA, R.Z. et al. Avaliação quantitativa de características produtivas e medidas lineares em rebanho leiteiro da raça Holandesa. PUBVET, Londrina, V. 8, N. 1, Ed. 250, Art. 1654, Janeiro, 2014.

Tabela 4. Estimativas de correlações simples da produção de leite diária e produção de leite ajustada para 305 dias com características lineares em vacas da raça Holandesa.

\begin{tabular}{|c|c|c|c|c|c|c|c|c|c|c|c|c|}
\hline & PLD & PLD305 & PC & PT & CC & AG & CT & DT & LI & LUP & CG & LB \\
\hline \multirow[t]{2}{*}{ PLD } & * & 0,85 & - & 0,0 & 0,0 & - & - & 0,0 & 0,1 & 0,2 & 0,1 & 0,1 \\
\hline & & & 0,10 & 8 & 7 & 0,06 & 0,07 & 3 & 5 & 3 & 0 & 5 \\
\hline \multirow[t]{2}{*}{ PLD305 } & & * & - & 0,1 & 0,0 & 0,03 & 0,02 & 0,0 & 0,1 & 0,2 & 0,0 & 0,1 \\
\hline & & & 0,11 & 0 & 4 & & & 9 & 2 & 1 & 9 & 0 \\
\hline \multirow[t]{2}{*}{ PC } & & & $*$ & 0,5 & 0,1 & 0,03 & 0,04 & 0,0 & 0,0 & 0,0 & 0,0 & 0,0 \\
\hline & & & & 4 & 0 & & & 6 & 4 & 9 & 4 & 6 \\
\hline \multirow[t]{2}{*}{ PT } & & & & * & 0,1 & 0,03 & 0,12 & 0,0 & 0,0 & 0,1 & 0,0 & 0,0 \\
\hline & & & & & 0 & & & 8 & 4 & 0 & 5 & 5 \\
\hline \multirow[t]{2}{*}{ CC } & & & & & $*$ & 0,10 & 0,04 & 0,0 & 0,0 & 0,0 & 0,0 & 0,0 \\
\hline & & & & & & & & 5 & 5 & 3 & 9 & 4 \\
\hline \multirow[t]{2}{*}{ AG } & & & & & & $*$ & 0,09 & 0,0 & 0,0 & 0,0 & 0,0 & 0,0 \\
\hline & & & & & & & & 6 & 2 & 8 & 4 & 5 \\
\hline \multirow[t]{2}{*}{ CT } & & & & & & & $*$ & 0,0 & 0,0 & 0,0 & 0,0 & 0,0 \\
\hline & & & & & & & & 6 & 3 & 6 & 6 & 8 \\
\hline \multirow[t]{2}{*}{ DT } & & & & & & & & $*$ & 0,0 & 0,0 & 0,0 & 0,0 \\
\hline & & & & & & & & & 6 & 5 & 6 & 3 \\
\hline \multirow[t]{2}{*}{ LI } & & & & & & & & & $*$ & 0,0 & 0,0 & 0,0 \\
\hline & & & & & & & & & & 4 & 4 & 1 \\
\hline \multirow[t]{2}{*}{ LUP } & & & & & & & & & & $*$ & 0,0 & 0,0 \\
\hline & & & & & & & & & & & 1 & 3 \\
\hline \multirow[t]{2}{*}{ CG } & & & & & & & & & & & $*$ & 0,0 \\
\hline & & & & & & & & & & & & 7 \\
\hline LB & & & & & & & & & & & & $*$ \\
\hline
\end{tabular}

Produção de leite diária - PLD; Produção de leite em 305 dias - PLD305; Peso corporal - PC; Perímetro torácico - PT; Comprimento corporal - CC; Altura de garupa - AG; Comprimento dos tetos - CT; Diâmetro dos tetos - DT; Largura do íleo - LI; Largura de úbere posterior - LUP; Comprimento de garupa - CG; Largura da boca LB. 
TAVEIRA, R.Z. et al. Avaliação quantitativa de características produtivas e medidas lineares em rebanho leiteiro da raça Holandesa. PUBVET, Londrina, V. 8, N. 1, Ed. 250, Art. 1654, Janeiro, 2014.

A maior estimativa pode ser verificada entre produção de leite diária e largura do úbere posterior. Este resultado encontra-se em concordância com os registros de MRODE e SWANSON (1994), os quais também verificaram correlação moderada e positiva entre produção de leite e largura do úbere posterior, no caso de 0,25, ligeiramente superior à encontrada nesse estudo $(0,23)$. Tendo em vista a produção média de leite ajustada para 305 dias (PML 305 dias) pode ser percebido que a produção média de leite aumentou em função do aumento da largura do úbere posterior das vacas, indicando que as possuidoras de úberes posteriores mais largos foram as mais produtivas. Esta associação positiva também foi registrada por ESTEVES et al. (2004).

Houve associação negativa e de baixa magnitude entre o peso corporal das vacas e a produção de leite diária e produção de leite ajustada para 305 dias, sendo de $-0,10$ e $-0,11$, respectivamente. Registra-se, portanto, que houve tendência de as vacas menos pesadas produzirem mais leite, o que pode ser explicado, pelo maior aporte de nutrientes da dieta ser alocado para a síntese de leite e não para a deposição muscular e de gordura. Entretanto, ESTEVES et al. (2004), estudando correlações genéticas e fenotípicas entre características de tipo e produção de leite em bovinos da raça Holandesa, não observaram comportamento claramente definido nessa associação, obtendo resultados variados.

A estimativa da correlação simples da largura da boca com a produção de leite e a produção de leite ajustada para 305 dias foi de 0,10 e 0,15, respectivamente, indicando que as vacas possuidoras de maior largura de boca tenderam a ser as mais produtivas, provavelmente, pela maior capacidade de apreensão do alimento em termos quantitativos.

\section{Conclusão}

A curvatura das pernas deve ser incluída no programa de acasalamentos do rebanho, visando obter animais com melhores pontuações, sob o risco de prejuízos nos aspectos produtivos e reprodutivos. 
TAVEIRA, R.Z. et al. Avaliação quantitativa de características produtivas e medidas lineares em rebanho leiteiro da raça Holandesa. PUBVET, Londrina, V. 8, N. 1, Ed. 250, Art. 1654, Janeiro, 2014.

Pode ser adotada a seleção a favor de menor tamanho corporal das vacas, tendo em vista a melhor relação custo - benefício entre os custos de produção do leite e a produtividade dos animais.

A largura do úbere posterior pode ser utilizada como característica auxiliar no processo de seleção de vacas da raça Holandesa.

\section{Referências Bibliográficas}

BROTHERSTONE, S. Genetic and phenotypic correlations between linear type traits and production traits in Holstein-Friesian dairy cattle. Anim. Prod., v.59, p.183-187,1994.

ESTEVES, A.M.C.; BERGMANN, J.A.G.; COSTA, M.C.; DURÃES, C.N.; COSTA, H.M; SILVA. Correlações genéticas e fenotípicas entre características de tipo e produção de leite em bovinos da raça Holandesa. Arq. Bras. Med. Vet. Zootec., v.56, n.4, p.529-535, 2004.

FREITAS, A.F.; DURÃES, M.C.; TEIXEIRA, N.M. Parâmetros genéticos da produção de leite de animais da raça Holandesa mantidos em sistema intensivo de produção tipo freestall. RevistaBrasileira de Zootecnia. V. 29. N.6; p.2008-2012, 2000.

MRODE, R.A.; SWANSON, G.J.T. Genetic and phenotypic relationships between conformation and production traits in Ayrshire heifers. Anim.Prod., v.58, p.335-338, 1994.

MISZTAL, I.; LAWLOR, T.J.; SHORT, T.H. et al. Multiple-traits estimation of variance components of yield and type traits using an animal model. J. Dairy Sci., v.75, p.544-551, 1992.

SAS - STATISTICAL ANALYSIS SYSTEMS. User's guide: statistics.Cary: 2003. (CD-ROM).

ZAMBIANCHI, A.R.; FREITAS, M.A.; PEREIRA, C.S. Efeitos genéticos e de ambiente sobre produção de leite e intervalo de partos em rebanhos leiteiros monitorados por sistema de informação. Revista Brasileira de Zootecnia. V.28. n.6.1999. 